\title{
Commentary
}

\section{Food for thought on food environments in Canada}

\author{
Lana Vanderlee, PhD, Guest Editor; Mary R. L'Abbé, PhD
}

As a whole, the environments in which we make our food choices do not typically reinforce and support healthy behaviours. The Canadian food environment in which we live, work, and play is failing to provide and promote healthy diets; as a result, Canada has seen high and continually rising rates of overweight and obesity and diet-related non-communicable diseases (NCDs) across the life course and among all sectors of society, with particularly high rates among vulnerable populations (such as Indigenous populations and those with low socioeconomic status). Swinburn and colleagues conceptualized the food environment as "the collective physical, economic, policy and sociocultural surroundings, opportunities and conditions that influence people's food and beverage choices and nutritional status." The scope of what is captured by the term "food environment" is broad, and includes such areas as food access and availability; food promotion and pricing; food labelling; the nutritional composition of the food supply and foods provided in public and private sector settings; and the retail food environment. These areas are influenced by the major actors that play roles in establishing a healthy food environment, including government (health, education, agriculture, finance, and international trade, among others), the food industry, and civil society more broadly.

Importantly, policies, interventions and actions aimed at improving the food environment shift the responsibility for improving dietary habits from individual responsibility for behaviours and choices to the collective environmental factors that support (or discourage) healthy food choices. This population-level approach works to shift the curve for both the highrisk and general populations, and focuses on interventions that have a broad reach and scope, while acknowledging the variety of societal factors that drive social norms and social structures that can endorse or impede healthy behaviours. Health-promoting food environments serve to make the healthy choice not only the easy choice, but also the most accessible, available, affordable, and preferred choice for consumers. ${ }^{2}$

Globally, there appears to be a significant window for policy action to address the food environment. The United Nations (UN) Political Declaration of the High-level Meeting of the General Assembly on the Prevention and Control of Non-communicable Diseases $^{3}$ in 2011 set the stage for global efforts combating diet-related NCDs, which led to the World Health Organization's (WHO) Global Action Plan for the Prevention and Control of NCDs. ${ }^{4}$ Subsequently, the WHO Report of the Commission on Ending Childhood Obesity ${ }^{5}$ and Set of Recommendations on the Marketing of Foods and Non-alcoholic Beverages to Children ${ }^{6}$ set out strong policy recommendations for improving aspects of the food environment, among other major documents and efforts. At the country level, Brazil's revolutionary food guide ${ }^{7}$, which encompasses a holistic view of healthy eating, Mexico's excise tax on beverages with sugar and calorically-dense foods ${ }^{8}$, and Chile's comprehensive policies on food labelling and marketing to children ${ }^{9}$ are a few examples of cutting edge policies that have been implemented to support and reinforce a healthy food environment. Within Canada, the announcement of the Healthy Eating Strategy $y^{10}$ will, if fully implemented, position Canada as a world leader in tackling multiple dimensions of the food environment through innovative and comprehensive policy and programming.
The September and October special issues of this journal aim to deconstruct aspects of the Canadian food environment across a variety of domains, and demonstrate some of the opportunities for major actors to take action in this area. In this September issue, the article by Potvin Kent et al. ${ }^{11}$ examines the relative 'healthiness' of breakfast cereals in the Canadian food supply, which are commonly targeted towards children and families via advertising on food packages and in mainstream media channels. They found that the nutritional profile of cereals with advertising targeted towards children was of particularly poor quality. The article by Prowse $^{12}$ examines food marketing policies using a settings-based approach to determine what policies are currently in place to limit the power and the exposure of marketing to young audiences who are particularly vulnerable to such practices. Both the Potvin Kent and Prowse articles highlight policy options for decreasing the impact of marketing as well as the need to engage with the food industry to move forward on an agenda for improving the quality of the food supply.

Jalbert-Arsenault et al. ${ }^{13}$ explore aspects of marketing and promotion of foods within supermarkets, one of the most proximal retail environments that can significantly influence consumer food choices at the point of sale. They used a tool developed to measure the availability, price, promotion and placement of healthful (i.e., vegetables and fruit) and less healthful (i.e., ultra-processed food products and carbonated beverage) items. The great variation in retail environments between different chain supermarkets in one low-to-mediumincome neighbourhood in Montréal, and the high proportion of larger retailers promoting the sale of ultra-processed food products to a greater extent than their 
healthier counterparts, defies the common definition of supermarkets as 'healthy' food outlets and highlights the opportunity for health promotion within consumer retail food environments.

The article by Orava and colleagues ${ }^{14}$ explores the implementation of mandatory nutrition standards in school settings in Ontario to promote healthy eating among students using a Comprehensive School Health approach. Orava identifies that while the physical environment within schools may support healthy eating, the social environment is not uniformly conducive to improving healthy eating. Engaging with stakeholders and champions within programs is likely to increase uptake and implementation of policy. The article provides insight into the importance of the context within which policy is it implemented, and a need for a policy approach to implementing Comprehensive School Health to promote healthy eating and behaviours in the school environment.

Lastly, with increasing global activity in food environment policy, monitoring is critical to understand the extent of implementation and evaluate the impact of policy. In this September issue, Boucher and colleagues $^{15}$ explore indicators of healthy food access, food literacy, and food environments using publicly available data already collected in Ontario and in Canada, and identify major gaps that currently prevent thorough monitoring in Ontario. As efforts to improve the food environment move forward in Canada, comprehensive data at the federal, provincial and municipal levels will be increasingly required to map and monitor progress in improving both the food environment and dietary habits. Within Canada, Raine and colleagues have developed the Report Card for Healthy Environments that is currently used in Alberta to comprehensively monitor the status of the food environment and provide recommendations for action. ${ }^{16}$ This is on trend with efforts to monitor food environments globally, such as the International Network for Food and Obesity/noncommunicable Diseases Research, Monitoring and Action Support (INFORMAS). INFORMAS is a group of academic and public-sector stakeholders who have worked to collectively establish a set of common methods which can be used to monitor food environments globally, and this work is ongoing in Canada. ${ }^{1}$
The diversity of articles in this special issue underscores the breadth of work being conducted within Canada to fill evidence gaps and inform policy to address healthy eating. Dietary behaviours are the leading behavioural risk factor for death globally, greater than tobacco, alcohol use, and physical inactivity. ${ }^{17}$ As policies and interventions are implemented in Canada to shift the food environment towards one that is health-promoting, the monitoring and subsequent evaluation of the impact of these efforts will be critical to identify future directions to improve the diet and health of Canadians.

\section{References}

1. Swinburn B, Sacks G, Vandevijvere S, et al. INFORMAS (International Network for Food and Obesity/ non-communicable diseases Research, Monitoring and Action Support): overview and key principles. Obes Rev. 2013;14(S1):1. doi: 10.1111/obr .12087 .

2. Hawkes C, Smith TG, Jewell J, et al. Smart food policies for obesity prevention. Lancet. 2015;385(9985):241021. doi: 10.1016/S0140-6736(14)61745-1.

3. UN General Assembly. Political declaration of the high-level meeting of the general assembly on the prevention and control of non-communicable diseases [Internet] UN. New York (New York): WHO; 2011 [cited July 20, 2017]. Available from: www.who .int/nmh/events/un_ncd_summit2011 /en/

4. World Health Organization (WHO). Global action plan for the prevention and control of noncommunicable diseases 2013-2020 [Internet]. Geneva (CH): WHO. 2013 [cited July 20, 2017]. Available from: http://www .who.int/nmh/publications/en/

5. World Health Organization (WHO). Report of the commission on ending childhood obesity. 2016 [Internet]. Geneva (CH): WHO. 2016 [cited July 20, 2017]. Available from: http:// www.who.int/end-childhood-obesity /final-report/en/

6. World Health Organization (WHO) Set of recommendations on the marketing of foods and non-alcoholic beverages to children [Internet]. Geneva (CH): WHO. 2010 [cited July 20, 2017]. Available from: http://www.who.int /dietphysicalactivity/publications /recsmarketing/en/
7. Ministry of Health of Brazil. Dietary guidelines for the Brazilian population [Internet] Brasilia (Brazil). 2014 [cited July 20, 2017]. Available from: http://www.foodpolitics.com/wp -content/uploads/Brazilian-Dietary -Guidelines-2014.pdf

8. Colchero MA, Popkin BM, Rivera JA, $\mathrm{Ng}$ SW. Beverage purchases from stores in Mexico under the excise tax on sugar sweetened beverages: observational study. BMJ. 2016;352:h6704. doi: https://doi.org/10.1136/bmj.h6704.

9. Diario Oficial de La Republica de Chile. Decreto 13 - Reglamento Ley 20.606 sobre Composición Nutricional de los Alimentos y su Publicidad [Internet]. 2015 [cited July 20, 2017]. Available from: http://www.dinta.cl /wp-dintacl/wp-content/uploads /Decreto-13_Ley-super8_do-20150626 .pdf

10. Government of Canada. Health Canada's healthy eating strategy [Internet]. 2016 [cited July 20, 2017]. Available from: https://www.canada.ca/en /services/health/campaigns/vision -healthy-canada/healthy-eating.html

11. Potvin Kent M, Cameron C, Philippe $\mathrm{S}$. The healthfulness and prominence of sugar in child-targeted breakfast cereals in Canada. Health Promot Chronic Dis Prev Can. 2017;37(9): 266-73.

12. Prowse R. Food marketing to children in Canada: a setting-based scoping review on exposure, power and impact. Health Promot Chronic Dis Prev Can. 2017;37(9):274-92.

13. Jalbert-Arsenault E, Robitaille E, Paquette M-C. Development, reliability and use of a food store survey to measure the supermarket food environment in a low- to medium-income area of Montreal. Health Promot Chronic Dis Prev Can. 2017;37(9): 293-302.

14. Orava T, Manske S, Hanning R. Support for healthy eating at schools according to the comprehensive school health framework: evaluation during the early years of the Ontario School Food and Beverage Policy implementation. Health Promot Chronic Dis Prev Can. 2017;37(9):303-12. 
15. Boucher BA, Manafo E, Boddy MR, Roblin RD, Truscott R. The Ontario Food and Nutrition Strategy: identifying indicators of food access and food litteracy for early monitoring of the food environment. Health Promot Chronic Dis Prev Can. 2017;37(9): 313-9.

16. Olstad DL, Raine KD, Nykiforuk CI. Development of a report card on healthy food environments and nutrition for children in Canada. Prev Med. 2014;69:287-95.

17. Institute of Health Metrics and Evaluation (IHME). GBD Compare Data Visualization [Internet]. Seatle (WA): IHME; 2016 [cited July 20, 2017]. Available from: http://vizhub .healthdata.org/gbd-compare 